\title{
Porta-enxertos para a produção de mudas de cajueiro
}

\author{
Luiz Augusto Lopes Serrano(1), Dheyne Silva Melo(1), Carlos Alberto Kenji Taniguchi ${ }^{(1)}$, \\ Francisco das Chagas Vidal Neto(1) e Luiz Francinélio Cavalcante Júnior ${ }^{(2)}$
}

\begin{abstract}
${ }^{(1)}$ Embrapa Agroindústria Tropical, Rua Dra Sara Mesquita, oㅡ 2.270, Planalto do Pici, CEP $60511-110$ Fortaleza, CE. E-mail: luiz.serrano@embrapa.br, dheyne.melo@embrapa.br, carlos.taniguchi@embrapa.br, vidal.neto@embrapa.br (2)Universidade Federal do Ceará, Avenida Mister Hull, no 2.977, Campus do Pici, CEP 60021-970 Fortaleza, CE. E-mail: jragronomo_ce@hotmail.com
\end{abstract}

Resumo - O objetivo deste trabalho foi avaliar clones de cajueiro como porta-enxertos para quatro genótipos-copa. Foram avaliados como porta-enxertos os clones CCP 06, CCP 09, CCP 76, CCP 1001, Embrapa 50, Embrapa 51, BRS 189, BRS 226, BRS 253, BRS 265, BRS 274 e BRS 275 e, como copas, os clones CCP 76, BRS 189, BRS 226 e BRS 274. Aos 60 dias após a semeadura, os porta-enxertos foram avaliados quanto às características biométricas e quanto às taxas de germinação e de aptidão à enxertia. Aos 80 dias após a enxertia, foram avaliadas as taxas de sucesso da enxertia, a aptidão para o plantio e as características biométricas das mudas. Houve correlação negativa entre massa de semente e taxas de germinação e de aptidão à enxertia. BRS 226, BRS 253 e BRS 274 apresentaram taxas insatisfatórias de germinação e de aptidão à enxertia. As maiores taxas de plantas aptas ao plantio, para a copa CCP 76, ocorreram nos porta-enxertos CCP 06, CCP 76 e CCP 1001; para BRS 189, destacou-se o CCP 06; para BRS 226, destacaram-se CCP 06, Embrapa 50, Embrapa 51, BRS 189 e BRS 265; e, para BRS 274, os porta-enxertos CCP 06, CCP 76, CCP 1001, Embrapa 50, Embrapa 51 e BRS 189.

Termos para indexação: Anacardium occidentale, enxertia, genótipo-copa, germinação de semente, matéria seca total.

\section{Rootstocks for the production of grafted cashew seedlings}

Abstract - The objective of this work was to evaluate cashew clones as rootstocks for four scions. The clones CCP 06, CCP 09, CCP 76, CCP 1001, Embrapa 50, Embrapa 51, BRS 189, BRS 226, BRS 253, BRS 265, BRS 274, and BRS 275 were evaluated as rootstocks; and the clones CCP 76, BRS 189, BRS 226, and BRS 274 were evaluated as scions. At 60 days after sowing, the rootstocks were evaluated for their biometric characteristics, germination rate, and grafting ability. At 80 days after grafting, grafted seedlings were evaluated for their grafting success rates, planting ability, and biometric characteristics. Seed mass were negatively correlated with germination rate and grafting ability. BRS 226, BRS 253 and BRS 274 showed unsatisfactory germination rate and grafting ability. The highest planting ability rates for CCP 76 occurred with CCP 06 , CCP 76, and CCP 1001 as rootstocks; for BRS 189, with CCP 06; for BRS 226, with CCP 06, Embrapa 50, Embrapa 51, BRS 189, and BRS 265; and, for BRS 274, with CCP 06, CCP 76, CCP 1001, Embrapa 50, Embrapa 51, and BRS 189.

Index terms: Anacardium occidentale, grafting, scion, seed germination, total dry matter.

\section{Introdução}

O cajueiro (Anacardium occidentale L.) é uma planta nativa do Nordeste brasileiro e, em razão de sua adaptação às condições semiáridas dessa região, o seu cultivo representa uma das principais fontes de renda dos agricultores do Ceará, Rio Grande do Norte e Piauí. Apesar de o Brasil figurar como um dos principais produtores mundiais de castanha de caju, a produtividade é considerada baixa, em torno de $300 \mathrm{~kg} \mathrm{ha}^{-1}$ de castanhas (Instituto Brasileiro de Geografia e Estatística, 2013). Dentre os principais motivos dessa baixa produtividade, destaca-se a formação da maioria dos cajueirais por mudas oriundas de sementes de cajueiro-comum. Por ser de espécie alógama, as plantas desses cajueiros são heterozigotas, com grande variabilidade (Adjei \& Mante, 2007). Além disso, como consequência da endogamia, os cajueiros seminais tendem a ser menos produtivos do que seus genitores (Paiva et al., 1998). Por estas razões, ainda hoje, muitos pomares são heterogêneos quanto ao porte das plantas, às características das castanhas e dos pedúnculos e, principalmente, quanto à tolerância 
ao estresse hídrico e às doenças, o que causa falhas no estande, com consequente queda da produtividade.

Na década de 1980, iniciou-se a geração de novas tecnologias para a cadeia produtiva do caju, em que se destaca a disponibilização de genótipos geneticamente superiores, com plantas de alto potencial de produção de frutos por unidade de área, porte baixo e produção precoce, denominados cajueiro-anão-precoce. Os primeiros clones de cajueiro-anão-precoce foram o CCP 06 e o CCP 76, disponibilizados em 1983 e, posteriormente, foram lançados os clones CCP 09, CCP 1001, Embrapa 50, Embrapa 51, BRS 189, BRS 226, BRS 253 e BRS 265. Em 2007, foram disponibilizados: o BRS 274, primeiro clone de cajueiro-comum; e o híbrido BRS 275, obtido do cruzamento entre cajueiro-comum e cajueiro-anão-precoce.

Os genótipos superiores de cajueiro são disponibilizados por meio de mudas enxertadas via garfagem lateral (Cavalcanti Júnior, 2005). Por meio da propagação vegetativa (clonagem), obtêm-se pomares com plantas homogêneas quanto ao porte e à produção, o que facilita o manejo e incrementa a produtividade. No entanto, verificam-se, ainda, na região produtora, diferenças na produção de frutos de pomares com um mesmo genótipo-copa, mas com porta-enxertos diferentes e ou de origens desconhecidas.

$\mathrm{Na}$ fruticultura, os porta-enxertos são selecionados pelas características que conferem à copa, das quais destacam-se o vigor, a tolerância a pragas e doenças, a precocidade, e os incrementos na produção e nos atributos de qualidade dos frutos (Asante, 2001; Castle, 2010). Ademais, diferentes combinações entre porta-enxertos e copa resultam em alterações fisiológicas das plantas, que podem originar melhores adaptações a diferentes condições ambientais (Paiva et al., 2008). Alguns autores evidenciam a existência de diferentes interações entre porta-enxertos e copas de cajueiro quanto à resistência às doenças (Cardoso et al., 2010), tolerância à salinidade (Carneiro et al., 2004; Ferreira-Silva et al., 2009; Sousa et al., 2011) e exigências hídricas (Oliveira et al., 2003). Ressaltese, ainda, a utilização de um número reduzido de genótipos, tanto como porta-enxerto quanto como copa, que caracteriza uma situação de vulnerabilidade genética a fatores bióticos ou abióticos que podem comprometer toda a cadeia produtiva (Melo Filho et al., 2006; Paiva et al., 2008).
Considerando-se que os genótipos superiores de cajueiro passaram pelos critérios técnicos de seleção, com destaque para a produção em condições de seca e tolerância ou resistência às doenças, é possível que estes materiais sejam promissores também como porta-enxertos.

O objetivo deste trabalho foi avaliar clones de cajueiro como porta-enxertos para quatro genótipos-copa na fase de formação das mudas.

\section{Material e Métodos}

$\mathrm{O}$ experimento foi realizado em viveiro telado por sombrite a 50\%, no Campo Experimental de Pacajus (CEP), Ceará, Brasil (4¹1'12"S, 38³0'01"W, e a 79 m de altitude). O município apresenta tipo climático Aw, conforme classificação de Köppen, com temperatura média anual de cerca de $26^{\circ} \mathrm{C}$.

Foram produzidos e avaliados como porta-enxertos todos os clones de cajueiro da Embrapa, registrados no Ministério da Agricultura, Pecuária e Abastecimento (Brasil, 2013), dos quais dez de cajueiro-anão-precoce, CCP 06, CCP 09, CCP 76, CCP 1001, Embrapa 50, Embrapa 51, BRS 189, BRS 226, BRS 253 e BRS 265; um de cajueiro-comum, BRS 274; e um híbrido, BRS 275. Utilizou-se o delineamento de blocos completos ao acaso, com quatro blocos (canteiros), com uma parcela experimental de cada tratamento (genótipo) com 133 plantas.

Os porta-enxertos foram produzidos em tubetes, com capacidade de $288 \mathrm{~mL}$, preenchidos com substrato composto pela mistura entre casca de arroz carbonizada, bagana de carnaúba triturada e solo hidromórfico (2:1:1). As análises física e química deste substrato, realizadas no Laboratório de Solos da Embrapa, Centro Nacional de Pesquisa em Agricultura Tropical (CNPAT), indicaram: densidade, 275,6 $\mathrm{kg} \mathrm{m}^{-3}$; CRA-10, 34,9\%; $\mathrm{pH}, 6,4$; condutividade elétrica, $0,3 \mathrm{dS} \mathrm{m}^{-1}$; carbono orgânico, 107,8 $\mathrm{g} \mathrm{kg}^{-1}$; N-total, 11,0 $\mathrm{g} \mathrm{kg}^{-1}$; Ca, $477 \mathrm{mg} \mathrm{L}^{-1} ; \mathrm{Mg}$, $290 \mathrm{mg} \mathrm{L}^{-1} ; \mathrm{K}, 315 \mathrm{mg} \mathrm{L}^{-1}$; Na, $52 \mathrm{mg} \mathrm{L}^{-1}$; P, $24 \mathrm{mg} \mathrm{L}^{-1}$; $\mathrm{Cl}, 709 \mathrm{mg} \mathrm{L}^{-1} ; \mathrm{N}^{-N_{3}}, 75 \mathrm{mg} \mathrm{L}^{-1} ; \mathrm{N}^{-N_{4}}, 1,6 \mathrm{mg} \mathrm{L}^{-1}$; $\mathrm{S}-\mathrm{SO}_{4}, 5,5 \mathrm{mg} \mathrm{L}^{-1}$.

A semeadura foi realizada em $28 / 3 / 2012$, tendose colocado uma semente por recipiente. Todas as sementes foram produzidas no CEP durante a safra de 2011. De cada lote de sementes dos genótipos utilizados, retirou-se uma amostra com 30 sementes 
para medida de comprimento, diâmetro e espessura centrais, com paquímetro digital, e da massa, em balança de precisão.

Aos 60 dias após a semeadura, época em que os porta-enxertos se apresentaram aptos à enxertia com aproximadamente $25 \mathrm{~cm}$ de altura, $5 \mathrm{~mm}$ de diâmetro de caule e oito folhas, conforme Cavalcanti Júnior (2005) -, realizou-se a avaliação dos seguintes coeficientes técnicos: taxa de germinação [(número de sementes germinadas / número de sementes semeadas) $\times 100$ ]; taxa de plântulas normais [(número de plantas sem anomalias / número de sementes germinadas) $\times 100$ ]; e taxa de plantas aptas à enxertia [(número de plântulas normais aptas à enxertia / número de sementes semeadas) $\times 100)]$. Foram consideradas como plântulas anormais, as que apresentavam algum tipo de anormalidade fisiológica como caulículo torto, nanismo e folhas mal formadas.

Em seguida, do centro de cada parcela experimental, retiraram-se amostras com dez plantas normais (no total de 40 plantas por genótipo), para avaliação da altura, do diâmetro de caule e do número de folhas. Posteriormente, as partes aéreas e os sistemas radiculares foram colocados para secar em estufa a $70^{\circ} \mathrm{C}$ por 72 horas e foram determinadas, em balança de precisão, as massas de matéria seca da parte aérea, do sistema radicular e total.

Aos 70 dias após a semeadura, selecionaram-se 54 plantas de cada genótipo (porta-enxerto), para serem enxertadas por garfagem lateral. No entanto, os genótipos BRS 226, BRS 253 e BRS 274 não apresentaram número de plantas suficientes para a enxertia, e foram, então, descartados como porta-enxertos. Os demais genótipos foram enxertados com garfos dos genótipos-copa CCP 76, BRS 189, BRS 226 e BRS 274. Nesta etapa, utilizou-se o delineamento de blocos ao acaso, em arranjo fatorial $9 \mathrm{x} 4$. Os tratamentos foram dispostos em três blocos (canteiros com bandejas), que continham uma parcela experimental de cada tratamento, composta por 18 plantas.

Os garfos utilizados foram obtidos dos jardins clonais de cajueiro localizados no CEP, que apresentavam aproximadamente $10 \mathrm{~cm}$ de comprimento e $5 \mathrm{~mm}$ de diâmetro, com gema terminal em início de brotação, conforme Cavalcanti Júnior (2005). Após a enxertia, os garfos foram protegidos com um saco de plástico transparente, para conservação da umidade. Decorridos
40 dias da enxertia (110 dias após a semeadura), as mudas foram retiradas do viveiro telado e colocadas na mesma disposição, em canteiros a pleno sol, para aclimatação. Nessa etapa, foram retirados os saquinhos que envolviam os garfos e as fitas de plástico utilizadas para fixar o garfo do genótipo-copa no caule do porta-enxerto.

Aos 80 dias após a enxertia (150 dias após a semeadura), as mudas de vários tratamentos já se apresentavam com as características recomendadas para o plantio em campo, com mínimo de $18 \mathrm{~cm}$ de altura e seis folhas expandidas, conforme Cavalcanti Júnior (2005). Nessa fase, determinou-se a taxa de sucesso da enxertia, dada pela relação entre o número de plantas enxertadas e o número de plantas aptas ao plantio em campo. Por meio das taxas de plantas aptas à enxertia e de sucesso da enxertia, estimou-se, para cada combinação entre porta-enxerto e copa, a taxa de plantas aptas ao plantio em campo. Posteriormente, foram avaliadas a altura, o diâmetro de caule e o número de folhas de sete plantas localizadas no centro de cada parcela experimental, no total de 21 plantas de cada combinação entre porta-enxerto e copa. Em seguida, a parte aérea e o sistema radicular das plantas foram colocados para secar em estufa a $70^{\circ} \mathrm{C}$ por 72 horas e foram determinadas as massas de matéria seca das folhas, dos caules, dos sistemas radiculares e totais.

Para efeito de análise, os valores dos coeficientes técnicos $(\%)$ foram transformados em $\operatorname{arc} \operatorname{sen}(\mathrm{x} / 100)^{0,5}$. Os dados obtidos foram submetidos à análise de variância $(\mathrm{p} \leq 0,05)$. As médias dos tratamentos foram comparadas pelo teste de Tukey a 5\% de probabilidade e foram determinadas as correlações de Pearson entre as características das sementes, dos porta-enxertos e das mudas.

\section{Resultados e Discussão}

Os genótipos de cajueiro apresentaram diferenças quanto ao tamanho e massa de sementes (castanhas), e às taxas de germinação, de plântulas normais e de plantas aptas à enxertia (Tabela 1). As sementes do clone de cajueiro-comum BRS 274 apresentaram os maiores valores de comprimento, diâmetro, espessura e massa, enquanto as sementes dos clones de cajueiro-anão-precoce CCP 06 e CCP 1001 apresentaram os menores valores para essas características. A diferença entre os clones de cajueiro 
com maior e menor massa de semente foi de $271 \%$, fato que mostra a alta variabilidade existente na espécie A. occidentale. As sementes do híbrido BRS 275 apresentaram massa média inferior à das sementes do BRS 274 e superior à das sementes de todos os genótipos de cajueiro-anão-precoce. Resultado semelhante foi observado por Paiva et al. (2008), que verificaram a superioridade de massa, comprimento e diâmetro das sementes do clone de cajueiro-comum BRS 274 (Comum 21) sobre as sementes do híbrido BRS 275 (Comum 31); e dessas sobre as de cajueiro-anão-precoce CCP 76 e CCP 06.

As maiores taxas de germinação foram obtidas pelas sementes dos clones CCP 06, CCP 76, Embrapa 50, Embrapa 51 e BRS 189, e a menor foi observada nas sementes do BRS 274 (Tabela 1). Elevadas taxas de germinação (92 a 94\%) de sementes do CCP 06 também foram observadas por Soares et al. (2000), Carneiro et al. (2002), Paiva et al. (2008) e Araujo et al. (2009). Do mesmo modo, Sousa et al. (2011) observaram que as sementes do BRS 274 apresentaram taxa de germinação de 46\%, considerada baixa. Para os outros clones de cajueiro, as taxas de germinação das sementes já registradas na literatura foram de: 91 e 95\% para CCP 1001 (Soares et al., 2000; Carneiro et al., 2002); 95 a 98\% para CCP 76 (Paiva et al., 2008; Araujo et al., 2009); 85\% para BRS 275 (Paiva et al., 2008); e 70\% para CCP 09 (Carneiro et al., 2002).
Foram constatadas correlações negativas entre a massa da semente e as taxas de germinação $\left(\mathrm{r}=-0,77^{*}\right)$ e de plantas aptas à enxertia $\left(\mathrm{r}=-0,84^{*}\right)$ para os genótipos de cajueiros avaliados. As sementes menores apresentaram elevadas taxas de germinação e de plantas aptas à enxertia. Segundo Nakagawa (1999), a absorção de água representa o primeiro passo para o processo de germinação, em que sementes de menor tamanho tendem a embeber água mais rápido e com maior volume proporcional, obtendo maiores índices de germinação. As sementes dos clones CCP 06 e CCP 76, que têm tamanho e massa menores, apresentaram elevadas taxas de germinação e de plântulas normais, o que resultou em maior número de plantas aptas à enxertia. O inverso foi observado com as sementes do clone BRS 274, de maior tamanho e massa, que apresentaram baixas taxas de germinação, de plântulas normais e de plantas aptas à enxertia. Por meio de tomografia de ressonância magnética, Paiva et al. (2004) identificaram que castanhas maiores apresentavam inúmeros defeitos relacionados à má formação dos cotilédones, além de espaços vazios entre eles e entre a amêndoa e o endocarpo. Estes defeitos podem comprometer tanto a germinação quanto a formação normal da plântula, pois, pelo fato de as sementes grandes terem mais espaços com ar, há maior dificuldade de absorção de água pelo embrião.

Tabela 1. Características morfométricas das sementes (castanhas) e taxas de germinação, plântula normal e plantas aptas à enxertia dos genótipos de cajueiro utilizados como porta-enxerto ${ }^{(1)}$.

\begin{tabular}{|c|c|c|c|c|c|c|c|c|}
\hline Genótipo & Tipo & $\begin{array}{c}\text { Comprimento } \\
(\mathrm{mm})\end{array}$ & $\begin{array}{c}\text { Diâmetro } \\
(\mathrm{mm})\end{array}$ & $\begin{array}{c}\text { Espessura } \\
(\mathrm{mm})\end{array}$ & $\begin{array}{c}\text { Massa } \\
(\mathrm{g})\end{array}$ & $\begin{array}{c}\text { Germinação } \\
(\%)\end{array}$ & $\begin{array}{c}\text { Plântulas } \\
\text { normais }(\%)\end{array}$ & $\begin{array}{c}\text { Plantas aptas à } \\
\text { enxertia }(\%)\end{array}$ \\
\hline ССР 06 & anão & $29,84 f$ & $18,52 \mathrm{f}$ & $16,83 f$ & $6,23 \mathrm{e}$ & $94,04 \mathrm{a}$ & $95,46 \mathrm{a}$ & $89,53 a$ \\
\hline ССР 09 & anão & $36,15 d$ & $22,84 b$ & $18,86 \mathrm{e}$ & $9,05 \mathrm{~d}$ & $71,15 \mathrm{~cd}$ & $90,77 \mathrm{abc}$ & $64,41 \mathrm{de}$ \\
\hline ССР 76 & anão & $32,48 \mathrm{e}$ & $21,30 \mathrm{de}$ & 19,44 de & $8,60 \mathrm{~d}$ & $90,68 \mathrm{a}$ & $91,47 \mathrm{ab}$ & $82,79 \mathrm{ab}$ \\
\hline CCP 1001 & anão & $29,45 f$ & $18,59 f$ & $17,27 f$ & $6,32 \mathrm{e}$ & $79,92 \mathrm{bc}$ & $88,82 \mathrm{abcd}$ & $70,85 \mathrm{~cd}$ \\
\hline Embrapa 50 & anão & $36,35 \mathrm{bcd}$ & $22,85 b$ & $18,77 \mathrm{e}$ & $10,64 \mathrm{c}$ & $90,38 \mathrm{a}$ & 82,39 bcde & $74,39 b c$ \\
\hline Embrapa 51 & anão & $36,18 \mathrm{~cd}$ & $21,88 \mathrm{~cd}$ & $18,95 \mathrm{e}$ & $10,70 \mathrm{c}$ & $88,26 a b$ & $81,18 \mathrm{cde}$ & $71,32 \mathrm{~cd}$ \\
\hline BRS 189 & anão & $32,58 \mathrm{e}$ & $20,97 \mathrm{e}$ & $18,92 \mathrm{e}$ & $8,37 d$ & $86,64 a b$ & $89,43 \mathrm{abcd}$ & $77,22 b c$ \\
\hline BRS 226 & anão & $35,23 d$ & $21,92 \mathrm{~cd}$ & $20,60 \mathrm{c}$ & $10,22 \mathrm{c}$ & $65,31 \mathrm{de}$ & $79,80 \mathrm{def}$ & $51,87 \mathrm{fg}$ \\
\hline BRS 253 & anão & $35,69 d$ & $22,52 \mathrm{bc}$ & $21,78 \mathrm{~b}$ & $11,10 \mathrm{c}$ & $60,91 \mathrm{e}$ & $77,28 \mathrm{ef}$ & $46,89 \mathrm{~g}$ \\
\hline BRS 265 & anão & $37,36 \mathrm{bc}$ & $22,45 b c$ & $19,99 \mathrm{~cd}$ & $10,25 \mathrm{c}$ & $73,29 \mathrm{~cd}$ & $87,84 \mathrm{abcd}$ & $64,28 \mathrm{de}$ \\
\hline BRS 274 & comum & $44,74 a$ & $27,67 \mathrm{a}$ & $22,84 a$ & $16,90 a$ & $25,57 f$ & $70,62 f$ & $17,85 \mathrm{~h}$ \\
\hline BRS 275 & híbrido & $37,41 b$ & $22,88 b$ & $21,90 \mathrm{~b}$ & $13,06 b$ & $76,28 \mathrm{c}$ & $80,23 \mathrm{def}$ & $60,56 \mathrm{ef}$ \\
\hline $\mathrm{CV}(\%)$ & - & 4,06 & 4,75 & 5,62 & 11,12 & 6,53 & 5,79 & 6,90 \\
\hline
\end{tabular}

${ }^{(1)}$ Médias seguidas de letras iguais, nas colunas, não diferem entre si, pelo teste de Tukey, a 5\% de probabilidade. Taxa de germinação, [(número de sementes germinadas / número de sementes semeadas) x 100]; taxa de plântulas normais, [(número de plantas sem anomalias / número de sementes germinadas) x 100]; e taxa de plantas aptas à enxertia, [(plantas aptas à enxertia / número de sementes semeadas) x 100]. Foram consideradas como plântulas anormais as que apresentavam algum tipo de anormalidade fisiológica como caulículo torto, nanismo e folhas mal formadas. 
Além das sementes do clone BRS 274, as dos clones BRS 226 e BRS 253 também apresentaram baixas taxas de germinação e de plântulas normais, o que resultou em menor número de plantas aptas à enxertia (Tabela 1), fato que inviabilizou a sua utilização na segunda etapa do experimento (fase de enxertia). Ademais, considerando-se que, na prática, os produtores de mudas de cajueiro julgam inviáveis economicamente os genótipos que apresentam rendimento de plantas aptas à enxertia abaixo dos $60 \%$, esses três clones de cajueiro foram considerados inviáveis como porta-enxertos.

Aos 60 dias após a semeadura, também foram constatadas diferenças entre as mudas dos porta-enxertos de cajueiro quanto às características de crescimento avaliadas (Tabela 2). Constatou-se elevada correlação $(\mathrm{r}=0,92 *)$ entre a massa da semente e a massa da matéria seca total da planta. As plantas do genótipo de cajueiro-comum BRS 274, oriundas das sementes mais pesadas, obtiveram as maiores médias de massas de matéria seca. $\mathrm{O}$ inverso foi observado nas plantas do cajueiro-anão-precoce CCP 06. Esses resultados corroboram os de Faluyi (1986), que constatou que plantas de cajueiro oriundas de sementes grandes são mais vigorosas do que aquelas provenientes de sementes pequenas, fato explicado pela maior reserva de nutrientes na amêndoa (cotilédones).

As plantas do cajueiro-comum BRS 274 apresentaram altura inferior à maioria dos demais genótipos, porém com diâmetro de caule superior a todos; e o inverso foi observado nas plantas de cajueiro-anão-precoce CCP 76, CCP 1001 e BRS 189 (Tabela 2). Resultados semelhantes foram observados por Paiva et al. (2008) em BRS 274, cujas plantas (seedlings) apresentaram diâmetro de caule superior às de cajueiro-anão-precoce; e por Soares et al. (2000) e Carneiro et al. (2002), que observaram que as plantas (seedlings) do CCP 1001 apresentaram maior altura e menor diâmetro do caule do que outros clones. O conhecimento da diferença entre os diâmetros do caule das plantas dos diferentes genótipos é importante para a tomada de decisão do momento da enxertia, pois, aquelas que apresentam maior diâmetro de caule poderão ser enxertadas mais precocemente. Assim, pelos resultados do presente trabalho, infere-se que as plantas de BRS 274, BRS 275, Embrapa 50 e BRS 265 podem atingir o ponto de enxertia mais precocemente do que os demais genótipos avaliados.

$\mathrm{O}$ acúmulo de matéria seca foi maior nas plantas de cajueiro-comum BRS 274 (Tabela 2). Entre os clones de cajueiro-anão-precoce, as plantas não diferiram quanto às massas da matéria seca da parte aérea e total e, quanto à massa de matéria seca do sistema radicular, houve diferença apenas entre as plantas dos clones CCP 06 e BRS 226. Ponte et al. (2011) verificaram que mudas de cajueiro-comum apresentaram alocação de massa mais intensificada na parte aérea do que as de seis clones de cajueiro-anão-precoce, tendo havido semelhança de acúmulo de matéria seca entre as plantas de cajueiro-anão-precoce, fato atribuído à baixa variabilidade genética desses genótipos.

Tabela 2. Características biométricas dos porta-enxertos de cajueiro, aos 60 dias após a semeadura ${ }^{(1)}$.

\begin{tabular}{|c|c|c|c|c|c|c|c|}
\hline Genótipo & Tipo & $\begin{array}{l}\text { Altura } \\
(\mathrm{cm})\end{array}$ & $\begin{array}{l}\text { Diâmetro do } \\
\text { caule (mm) }\end{array}$ & $\begin{array}{l}\text { Número } \\
\text { de folhas }\end{array}$ & $\begin{array}{r}\text { Matéria seca da } \\
\text { parte aérea }(\mathrm{g})\end{array}$ & $\begin{array}{c}\text { Matéria seca do } \\
\text { sistema radicular }(\mathrm{g})\end{array}$ & $\begin{array}{c}\text { Matéria seca } \\
\text { total }(\mathrm{g})\end{array}$ \\
\hline ССР 06 & Anão & $34,52 \mathrm{bc}$ & 4,91def & $10,82 \mathrm{e}$ & $2,20 \mathrm{c}$ & $0,43 \mathrm{c}$ & $2,63 \mathrm{c}$ \\
\hline ССР 09 & Anão & $38,80 \mathrm{a}$ & $5,13 \mathrm{cde}$ & $12,27 \mathrm{bcde}$ & $2,74 b c$ & $0,60 \mathrm{bc}$ & $3,34 b c$ \\
\hline ССР 76 & Anão & $36,99 \mathrm{ab}$ & $4,84 \mathrm{def}$ & $11,60 \mathrm{de}$ & $2,34 b c$ & $0,51 b c$ & $2,86 \mathrm{bc}$ \\
\hline CCP 1001 & Anão & $36,58 \mathrm{ab}$ & $4,70 \mathrm{f}$ & $11,82 \mathrm{cde}$ & $2,43 b c$ & $0,52 b c$ & $2,95 \mathrm{bc}$ \\
\hline Embrapa 50 & Anão & $34,14 \mathrm{bc}$ & $5,61 \mathrm{~b}$ & $10,82 \mathrm{e}$ & $2,46 b c$ & $0,63 b c$ & $3,10 \mathrm{bc}$ \\
\hline Embrapa 51 & Anão & $36,35 \mathrm{ab}$ & $5,20 \mathrm{~cd}$ & $12,00 \mathrm{bcde}$ & $2,79 b c$ & $0,58 \mathrm{bc}$ & $3,37 \mathrm{bc}$ \\
\hline BRS 189 & Anão & $37,46 \mathrm{ab}$ & $4,81 \mathrm{ef}$ & $13,45 \mathrm{ab}$ & $2,35 \mathrm{bc}$ & $0,62 b c$ & $2,97 \mathrm{bc}$ \\
\hline BRS 226 & Anão & $31,53 \mathrm{~cd}$ & $5,18 \mathrm{~cd}$ & $13,30 \mathrm{ab}$ & $2,61 b c$ & $0,77 \mathrm{~b}$ & $3,38 \mathrm{bc}$ \\
\hline BRS 253 & Anão & $30,84 \mathrm{~cd}$ & $5,20 \mathrm{~cd}$ & $12,20 \mathrm{bcde}$ & $2,80 \mathrm{bc}$ & $0,66 b c$ & $3,46 b c$ \\
\hline BRS 265 & Anão & $35,70 \mathrm{ab}$ & $5,42 \mathrm{bc}$ & $13,10 \mathrm{abc}$ & $2,87 \mathrm{bc}$ & $0,57 \mathrm{bc}$ & $3,44 \mathrm{bc}$ \\
\hline BRS 274 & Comum & $27,99 d$ & $6,25 \mathrm{a}$ & $13,75 \mathrm{a}$ & $4,15 \mathrm{a}$ & $1,29 \mathrm{a}$ & $5,44 \mathrm{a}$ \\
\hline BRS 275 & Híbrido & $34,19 \mathrm{bc}$ & $5,63 \mathrm{~b}$ & $12,75 \mathrm{abcd}$ & $3,07 \mathrm{~b}$ & $0,66 \mathrm{bc}$ & $3,74 \mathrm{~b}$ \\
\hline CV (\%) & - & 15,98 & 9,99 & 17,06 & 11,44 & 17,61 & 11,13 \\
\hline
\end{tabular}

${ }^{(1)}$ Médias seguidas de letras iguais, nas colunas, não diferem entre si, pelo teste de Tukey, a $5 \%$ de probabilidade. 
Aos 150 dias após a semeadura (equivalente a 80 dias após a enxertia), as taxas de sucesso da enxertia foram diferentes entre as combinações de porta-enxerto e copa (Tabela 3). As combinações com baixas taxas de sucesso de enxertia do genótipo-copa BRS 226 ocorreram com os porta-enxertos CCP 09, Embrapa 50 e CCP 76. No entanto, elevadas taxas de sucesso de enxertia foram obtidas pelos genótipos-copa CCP 76 e BRS 274 enxertados em todos os porta-enxertos, com exceção do CCP 76 no porta-enxerto BRS 265. O genótipo-copa BRS 189 apresentou maiores taxas de sucesso de enxertia com os porta-enxertos CCP 06, CCP 09, CCP 76 e CCP 1001. Elevadas taxas de compatibilidade de enxertia dos clones CCP 76 e BRS 274, em diversos porta-enxertos, também foram observadas por Silva et al. (2003), Melo Filho et al. (2006) e Paiva et al. (2008). Asante (2001) afirma que o sucesso da enxertia em Anacardiaceas está associado à relativa semelhança entre os diâmetros do porta-enxerto e do garfo do genótipo-copa.A partir dessa consideração, observou-se que, para os genótipos-copa CCP 76 e BRS 189, os porta-enxertos com menor diâmetro de caule (Tabela 2) proporcionaram as maiores taxas de enxertia (Tabela 3 ), o que se confirma pela correlação inversa entre esses parâmetros $(\mathrm{r}=-0,71 *)$. No entanto, para o genótipo-copa BRS 226, houve uma tendência de maior sucesso de enxertia em porta-enxertos com maior diâmetro de caule; e o genótipo-copa BRS 274 apresentou-se indiferente.

Os resultados obtidos no presente trabalho mostram que há diferenças de compatibilidade de enxertia entre os porta-enxertos e os genótipos-copa de cajueiro. Assim, é importante para os produtores de mudas de

Tabela 3. Taxas de sucesso da enxertia (\%), entre diferentes combinações de porta-enxerto e copa de cajueiro ${ }^{(1)}$.

\begin{tabular}{lllll}
\hline Porta-enxerto & \multicolumn{4}{c}{ Copa de cajueiro } \\
\cline { 2 - 5 } & \multicolumn{1}{c}{ CCP 76 } & BRS 189 & BRS 226 & BRS 274 \\
\hline CCP 06 & $87,61 \mathrm{Aa}$ & $94,95 \mathrm{Aa}$ & $55,65 \mathrm{Babc}$ & $76,72 \mathrm{ABa}$ \\
CCP 09 & $93,17 \mathrm{ABa}$ & $95,26 \mathrm{Aa}$ & $25,36 \mathrm{Cd}$ & $73,68 \mathrm{Ba}$ \\
CCP 76 & $76,90 \mathrm{Aab}$ & $75,97 \mathrm{Aab}$ & $40,52 \mathrm{Bbcd}$ & $76,26 \mathrm{Aa}$ \\
CCP 1001 & $70,60 \mathrm{Bab}$ & $92,34 \mathrm{Aa}$ & $68,75 \mathrm{Ba}$ & $80,14 \mathrm{ABa}$ \\
Embrapa 50 & $94,44 \mathrm{Aa}$ & $65,63 \mathrm{Bbc}$ & $31,77 \mathrm{Ccd}$ & $78,51 \mathrm{ABa}$ \\
Embrapa 51 & $84,36 \mathrm{Aa}$ & $55,65 \mathrm{Bbc}$ & $80,14 \mathrm{Aa}$ & $76,61 \mathrm{Aa}$ \\
BRS 189 & $81,00 \mathrm{Aab}$ & $46,27 \mathrm{Bc}$ & $77,95 \mathrm{Aa}$ & $84,36 \mathrm{Aa}$ \\
BRS 265 & $57,51 \mathrm{Bb}$ & $46,27 \mathrm{Bc}$ & $61,16 \mathrm{Bab}$ & $90,93 \mathrm{Aa}$ \\
BRS 275 & $83,59 \mathrm{Aa}$ & $65,38 \mathrm{Abc}$ & $70,52 \mathrm{Aa}$ & $72,94 \mathrm{Aa}$ \\
\hline
\end{tabular}

${ }^{(1)}$ Médias seguidas de letras iguais, maiúsculas nas linhas e minúsculas nas colunas, não diferem entre si, pelo teste de Tukey, a $5 \%$ de probabilidade. CV, $18,45 \%$. cajueiro a escolha de combinações que apresentem elevadas taxas de sucesso de enxertia, o que maximizará a eficiência produtiva do viveiro.

Quanto à taxa de mudas aptas ao plantio em campo, também foram verificadas diferenças entre as combinações de porta-enxertos e genótipos-copa de cajueiro (Tabela 4). As taxas de mudas aptas ao plantio variaram de 16,05 a 83,19\%. O genótipo-copa CCP 76 apresentou maior número de mudas aptas ao plantio em campo quando enxertado nos porta-enxertos CCP 06, CCP 76 e CCP 1001. Para o genótipo-copa BRS 189, destacou-se como porta-enxerto apenas o CCP 06; para o BRS 226, destacaram-se CCP 06, Embrapa 50, Embrapa 51, BRS 189 e BRS 265; e, para o BRS 274, destacaram-se o CCP 06, CCP 76, CCP 1001, Embrapa 50, Embrapa 51 e BRS 189. Nota-se que o porta-enxerto CCP 06 apresentou resultados satisfatórios para todos os genótipos-copa, principalmente, em razão de suas elevadas taxas de germinação, de plântulas normais, plantas aptas à enxertia (Tabela 1), e compatibilidade de enxertia (Tabela 3), logo, seu uso possibilita elevada eficiência no sistema de produção de mudas.

Houve diferenças entre as mudas de cajueiro quanto à maioria das características biométricas avaliadas; entretanto, interações significativas entre porta-enxertos e genótipos-copa foram observadas somente quanto à altura e o número de folhas (Tabelas 5 e 6). Para as mudas do genótipo-copa CCP 76, os porta-enxertos que propiciaram maiores altura e número de folhas foram CCP 76, Embrapa 50, Embrapa 51 eBRS 275 ; para as mudas do genótipo-copa

Tabela 4. Taxas de mudas de cajueiro aptas ao plantio em campo (\%), em relação ao número de sementes semeadas ${ }^{(1)}$.

\begin{tabular}{|c|c|c|c|c|}
\hline \multirow[t]{2}{*}{ Porta-enxerto } & \multicolumn{4}{|c|}{ Copa de cajueiro } \\
\hline & CCP 76 & BRS 189 & BRS 226 & BRS 274 \\
\hline CCP 06 & $78,12 \mathrm{ABa}$ & $83,19 \mathrm{Aa}$ & $49,58 \mathrm{Cab}$ & $68,32 \mathrm{Ba}$ \\
\hline ССР 09 & $57,32 \mathrm{ABbc}$ & $59,67 \mathrm{Abc}$ & $16,05 \mathrm{Cd}$ & $46,40 \mathrm{Bc}$ \\
\hline ССР 76 & $63,10 \mathrm{Aab}$ & $62,87 \mathrm{Ab}$ & $33,47 \mathrm{Bcd}$ & $62,94 \mathrm{Aab}$ \\
\hline CCP 1001 & $66,91 \mathrm{Aab}$ & $45,87 \mathrm{Bcd}$ & $22,15 \mathrm{Cd}$ & $55,15 \mathrm{ABabc}$ \\
\hline Embrapa 50 & $62,09 \mathrm{Ab}$ & $40,97 \mathrm{Bd}$ & $59,29 \mathrm{Aa}$ & $56,54 \mathrm{Aabc}$ \\
\hline Embrapa 51 & $56,87 \mathrm{Abc}$ & $32,39 \mathrm{Bd}$ & $54,25 \mathrm{Aab}$ & 59,49Aabc \\
\hline BRS 189 & $44,25 \mathrm{Bc}$ & $35,57 \mathrm{Bd}$ & $47,18 \mathrm{Babc}$ & $70,09 \mathrm{Aa}$ \\
\hline BRS 265 & $53,57 \mathrm{Abc}$ & $41,46 \mathrm{Ad}$ & $45,23 \mathrm{Aabc}$ & $46,36 \mathrm{Ac}$ \\
\hline BRS 275 & $42,59 \mathrm{Ac}$ & $53,85 \mathrm{Abc}$ & $41,46 \mathrm{Abc}$ & $48,22 \mathrm{Abc}$ \\
\hline
\end{tabular}

${ }^{(1)}$ Médias seguidas de letras iguais, maiúsculas nas linhas e minúsculas nas colunas, não diferem entre si, pelo teste de Tukey, a $5 \%$ de probabilidade. $\mathrm{CV}, 12,94 \%$. Mudas consideradas aptas ao plantio, com mínimo de $18 \mathrm{~cm}$ de altura e seis folhas expandidas (Cavalcanti Júnior, 2005). 
BRS 189, destacaram-se Embrapa 50, Embrapa 51, BRS 265 e BRS 275 ; e, para o genótipo-copa BRS 274, destacaram-se os porta-enxertos CCP 06 e CCP 09. Nota-se que, para as mudas dos três genótipos-copa de cajueiro-anão-precoce - CCP 76, BRS 189 e BRS 226-, os porta-enxertos Embrapa 50, Embrapa 51 e BRS 275 se destacaram por propiciar mudas maiores e com maior número médio de folhas.

Quanto às demais características biométricas das mudas, não houve interação entre genótipos-copa e porta-enxertos. Observou-se que, em geral, o porta-enxerto BRS 275 conferiu os maiores valores, quanto a essas características, às mudas de todos os genótipos-copa avaliados, em que se destacam também os porta-enxertos Embrapa 50 e Embrapa 51 (Tabela 6). Considerando-se apenas os genótipos-copa, constatouse pouca variação no crescimento das mudas, com uma diferença mais notável na maior massa da matéria seca total das mudas do clone BRS 274, que, no entanto, não diferiu das do clone BRS 189. Não houve efeito dos genótipos sobre a massa de matéria seca do sistema radicular, possivelmente, em consequência do espaço restrito para crescimento das raízes nos tubetes com capacidade de $288 \mathrm{~mL}$.

Os genótipos de cajueiro da Embrapa, quando utilizados como porta-enxertos, apresentam diferenças

Tabela 5. Altura e número de folhas das mudas de cajueiro, oriundas de diferentes combinações de porta-enxerto e copa, aos 150 dias após a semeadura (80 dias após a enxertia) $)^{(1)}$.

\begin{tabular}{|c|c|c|c|c|c|c|c|c|}
\hline \multirow[t]{2}{*}{ Porta-Enxerto } & \multicolumn{4}{|c|}{ Altura $(\mathrm{cm})$} & \multicolumn{4}{|c|}{ Número de folhas } \\
\hline & CCP 76 & BRS 189 & BRS 226 & BRS 274 & CCP 76 & BRS 189 & BRS 226 & BRS 274 \\
\hline CCP 06 & $22,73 \mathrm{Bc}$ & $23,37 \mathrm{Bbc}$ & $20,92 \mathrm{Cb}$ & $25,52 \mathrm{Aa}$ & $5,43 \mathrm{Ab}$ & $5,57 \mathrm{Ac}$ & $6,00 \mathrm{Ab}$ & $6,52 \mathrm{Aab}$ \\
\hline ССР 09 & $23,07 \mathrm{BCbc}$ & $23,19 \mathrm{Bbc}$ & $21,74 \mathrm{Cab}$ & $24,73 \mathrm{Aab}$ & $5,95 \mathrm{Aab}$ & $5,71 \mathrm{Ac}$ & $5,76 \mathrm{Ab}$ & $6,52 \mathrm{Aab}$ \\
\hline CCP 76 & 23,94Aabc & $23,23 \mathrm{Abc}$ & 21,49Bab & $22,66 \mathrm{ABc}$ & $6,76 \mathrm{Aab}$ & $6,05 \mathrm{Abc}$ & $6,71 \mathrm{Aab}$ & $5,61 \mathrm{Ab}$ \\
\hline CCP 1001 & $22,88 \mathrm{ABc}$ & $23,97 \mathrm{Abc}$ & $22,09 \mathrm{Bab}$ & $22,15 \mathrm{Bc}$ & $5,33 \mathrm{Bb}$ & $5,86 \mathrm{ABbc}$ & $6,95 \mathrm{Aab}$ & $5,95 \mathrm{ABab}$ \\
\hline Embrapa 50 & $24,60 \mathrm{Bab}$ & $26,09 \mathrm{Aa}$ & $22,95 \mathrm{Ca}$ & $22,37 \mathrm{Cc}$ & $6,05 \mathrm{Bab}$ & 7,62Aa & $6,81 \mathrm{ABab}$ & 6,09Bab \\
\hline Embrapa 51 & $24,75 \mathrm{Aab}$ & $24,73 \mathrm{Aab}$ & $22,33 \mathrm{Bab}$ & $23,68 \mathrm{ABbc}$ & $6,57 \mathrm{Aab}$ & $7,62 \mathrm{Aa}$ & $7,00 \mathrm{Aa}$ & $6,76 \mathrm{Aab}$ \\
\hline BRS 189 & $23,12 \mathrm{Abc}$ & $22,99 \mathrm{Ac}$ & $22,37 \mathrm{Aab}$ & $23,21 \mathrm{Abc}$ & $6,48 \mathrm{Bab}$ & $6,19 \mathrm{Babc}$ & $7,71 \mathrm{Aa}$ & $6,43 \mathrm{Bab}$ \\
\hline BRS 265 & $23,19 \mathrm{Abc}$ & $24,51 \mathrm{Aabc}$ & $21,76 \mathrm{Bab}$ & $23,60 \mathrm{Abc}$ & $6,62 \mathrm{Aab}$ & $6,28 \mathrm{Aabc}$ & $6,38 \mathrm{Aab}$ & $6,71 \mathrm{Aab}$ \\
\hline BRS 275 & $25,48 \mathrm{Aa}$ & $26,19 \mathrm{Aa}$ & $22,65 \mathrm{Ba}$ & $23,57 \mathrm{Bbc}$ & 7,09Aa & 7,23Aab & 7,57Aa & $7,28 \mathrm{Aa}$ \\
\hline CV (\%) & \multicolumn{4}{|c|}{8,40} & \multicolumn{4}{|c|}{26,13} \\
\hline
\end{tabular}

${ }^{(1)}$ Médias seguidas de letras iguais, maiúsculas nas linhas e minúsculas nas colunas, não diferem entre si, pelo teste de Tukey, a $5 \%$ de probabilidade.

Tabela 6. Características de mudas de quatro genótipos-copa de cajueiro, enxertados em diferentes porta-enxertos, aos 150 dias após a semeadura (80 dias após a enxertia) $)^{(1)}$.

\begin{tabular}{|c|c|c|c|c|c|}
\hline Genótipos & $\begin{array}{c}\text { Diâmetro do } \\
\text { caule (mm) }\end{array}$ & $\begin{array}{l}\text { Matéria seca } \\
\text { das folhas }(\mathrm{g})\end{array}$ & $\begin{array}{c}\text { Matéria seca } \\
\text { da parte aérea }(\mathrm{g})\end{array}$ & $\begin{array}{c}\text { Matéria seca do } \\
\text { sistema radicular }(\mathrm{g})\end{array}$ & $\begin{array}{c}\text { Matéria seca } \\
\text { total }(\mathrm{g})\end{array}$ \\
\hline \multicolumn{6}{|l|}{ Porta-enxerto } \\
\hline ССР 06 & $6,59 \mathrm{de}$ & $0,81 b$ & $2,10 \mathrm{bc}$ & $1,13 \mathrm{a}$ & $4,04 b$ \\
\hline ССР 09 & $6,75 \mathrm{~cd}$ & $0,90 \mathrm{~b}$ & $2,15 b c$ & $1,15 \mathrm{a}$ & $4,20 \mathrm{~b}$ \\
\hline CCP 76 & $6,43 \mathrm{e}$ & $0,82 b$ & $1,90 \mathrm{c}$ & $1,01 \mathrm{a}$ & $3,73 b$ \\
\hline CCP 1001 & $6,72 \mathrm{cde}$ & $0,92 b$ & $2,15 \mathrm{abc}$ & $1,27 \mathrm{a}$ & $4,34 \mathrm{ab}$ \\
\hline Embrapa 50 & $7,06 \mathrm{ab}$ & $0,93 b$ & $2,29 \mathrm{ab}$ & $1,11 \mathrm{a}$ & $4,33 \mathrm{ab}$ \\
\hline Embrapa 51 & $6,94 a b c$ & $0,93 b$ & $2,29 \mathrm{ab}$ & $1,13 \mathrm{a}$ & $4,36 \mathrm{ab}$ \\
\hline BRS 189 & $6,58 \mathrm{de}$ & $0,92 b$ & $2,08 \mathrm{bc}$ & $1,18 \mathrm{a}$ & $4,18 b$ \\
\hline BRS 265 & $6,84 \mathrm{bcd}$ & $0,97 b$ & $2,23 \mathrm{abc}$ & $1,08 \mathrm{a}$ & $4,28 \mathrm{ab}$ \\
\hline BRS 275 & $7,18 \mathrm{a}$ & $1,14 \mathrm{a}$ & $2,49 \mathrm{a}$ & $1,28 \mathrm{a}$ & 4,91a \\
\hline \multicolumn{6}{|l|}{ Copa } \\
\hline CCP 76 & $6,70 \mathrm{a}$ & $0,97 \mathrm{a}$ & $2,06 b$ & $1,13 \mathrm{a}$ & $4,16 b$ \\
\hline BRS 189 & $6,80 \mathrm{a}$ & $0,87 b$ & $2,18 b$ & $1,18 \mathrm{a}$ & $4,24 \mathrm{ab}$ \\
\hline BRS 226 & $6,82 \mathrm{a}$ & $0,89 \mathrm{ab}$ & $2,07 b$ & $1,12 \mathrm{a}$ & $4,08 b$ \\
\hline BRS 274 & $6,84 a$ & $0,98 \mathrm{a}$ & $2,43 \mathrm{a}$ & $1,17 \mathrm{a}$ & $4,58 \mathrm{a}$ \\
\hline$\overline{C V}(\%)$ & 10,38 & 13,69 & 11,84 & 19,33 & 11,98 \\
\hline
\end{tabular}

${ }^{(1)}$ Médias seguidas de letras iguais, nas colunas, não diferem entre si, pelo teste de Tukey, a 5\% de probabilidade. 
entre si quanto aos coeficientes técnicos de produção e crescimento das mudas, além de diferirem nas interações com os genótipos-copa. Assim, sugerese que as combinações mais promissoras entre porta-enxerto e copa, sejam avaliadas em condições de campo, quanto à produção de frutos e quanto à tolerância ao estresse hídrico, a pragas e a doenças.

\section{Conclusões}

1. Há correlação inversa entre a massa da semente de cajueiro e as taxas de germinação e de plantas aptas à enxertia.

2. Os genótipos de cajueiro BRS 226, BRS 253 e BRS 274 não apresentam potencial técnico para uso como porta-enxertos, em razão das baixas taxas de germinação e de plantas aptas à enxertia.

3. As maiores taxas de mudas aptas ao plantio em campo para o genótipo-copa CCP 76 são obtidas com os porta-enxertos CCP 06, CCP 76 e CCP 1001; para o genótipo-copa BRS 189, o porta-enxerto CCP 06; para o genótipo-copa BRS 226, os porta-enxertos CCP 06, Embrapa 50, Embrapa 51, BRS 189 e BRS 265; e, para o genótipo-copa BRS 274, os porta-enxertos CCP 06, CCP 76, CCP 1001, Embrapa 50, Embrapa 51 e BRS 189.

4. Os genótipos-copa BRS 226 e BRS 274 apresentaram o maior número de porta-enxertos compatíveis para produção de mudas aptas à enxertia, e o genótipo-copa BRS 189 foi o que apresentou maior especificidade.

\section{Agradecimentos}

Aos funcionários Raimundo Nonato Martins de Souza, José Erivaldo Rodrigues, Antônio Fialho Bento e Raimundo Sena da Silva do viveiro de mudas do Campo Experimental da Embrapa, em Pacajus, Ceará, pelo apoio operacional.

\section{Referências}

ADJEI, P.Y.; MANTE, D. Sources of rootstock, scion wood type, and duration of scion defoliation on graft success in cashew (Anacardium occidentale L.). Ghana Journal of Horticulture, v.6, p.59-64, 2007.

ARAUJO, J.R.G.; CERQUEIRA, M.C.M.; GUISCEM, J.M.; MARTINS, M.R.; SANTOS, F.N. dos; MENDONÇA, M.C.S. Embebição e posição da semente na germinação de clones de porta-enxertos de cajueiro-anão-precoce. Revista Brasileira de Fruticultura, v.31, p.552-558, 2009. DOI: 10.1590/ S0100-29452009000200033.

ASANTE, A.K. Compatibility studies on cashew-mango graft combinations. Ghana Journal of Horticulture, v.34, p.3-9, 2001.

BRASIL. Ministério da Agricultura, Pecuária e Abastecimento. Cultivares registradas. Disponível em: < extranet.agricultura.gov. $\mathrm{br} / \mathrm{php} / \mathrm{snpc} /$ cultivarweb/cultivares_registradas.php $>$. Acesso em: 2 maio 2013.

CARDOSO, J.E.; CAVALCANTI, J.J.V.; CYSNE, A.Q.; SOUSA, T.R.M. de; CORRÊA, M.C. de M. Interação enxerto e porta-enxerto na incidência da resinose do cajueiro. Revista Brasileira de Fruticultura, v.32, p.847-854, 2010. DOI: 10.1590/ S0100-29452010005000101.

CARNEIRO, P.T.; FERNANDES, P.D.; GHEYI, H.R.; SOARES, F.A.L. Germinação e crescimento inicial de genótipos de cajueiro anão-precoce em condições de salinidade. Revista Brasileira de Engenharia Agrícola e Ambiental, v.6, p.199-206, 2002. DOI: 10.1590/S1415-43662002000200003.

CARNEIRO, P.T.; FERNANDES, P.D.; GHEYI, H.R.; SOARES, F.A.L.; VIANA, S.B.A. Salt tolerance of precocious-dwarf cashew rootstocks - physiological and growth indexes. Scientia Agricola, v.61, p.9-16, 2004. DOI: 10.1590/S0103-90162004000100002.

CASTLE, W.S. A career perspective on citrus rootstocks, their development, and commercialization. HortScience, v.45, p.11-15, 2010.

CAVALCANTI JÚNIOR, A.T. Mudas: padrões e exigências agronômicas. In: OLIVEIRA, V.H. de; COSTA, V.S. de O. (Ed.). Manual de produção integrada de caju. Fortaleza: Embrapa Agroindústria Tropical, 2005. p.111-120.

FALUYI, M.A. Investigations on seedling vigour in cashew (Anacardium occidentale L.). Plant Breeding, v.97, p.237-245, 1986. DOI: 10.1111/j.1439-0523.1986.tb01059.x.

FERREIRA-SILVA, S.L.; VOIGT, E.L.; VIÉGAS, R.A.; PAIVA, J.R. de; SILVEIRA, J.A.G. Influência de porta-enxertos na resistência de mudas de cajueiro ao estresse salino. Pesquisa Agropecuária Brasileira, v.44, p.361-367, 2009. DOI: 10.1590/ S0100-204X2009000400005.

INSTITUTO BRASILEIRO DE GEOGRAFIA E ESTATÍSTICA. Sistema IBGE de recuperação automática. Disponível em: $<$ http//www.sidra.ibge.gov.br>. Acesso em: 05 mar. 2013.

MELO FILHO, O.M. de; COSTA, J.T.A.; CAVALCANTE JUNIOR, A.T.; BEZERRA, M.A.; MESQUITA, R.C.M. Caracterização biométrica, crescimento de plântulas e pega de enxertia de novos porta-enxertos de cajueiro-anão-precoce. Revista Ciência Agronômica, v.37, p.332-338, 2006.

NAKAGAWA, J. Testes de vigor baseado no desempenho das plântulas. In: KRZYZANOWSKI, F.C.; VIEIRA, R.D.; FRANCA NETO, J. de B. (Ed.). Vigor de sementes: conceitos e testes. Londrina: Abrates, 1999. 218p.

OLIVEIRA, V.H. de; BARROS, L. de M.; LIMA, R.N. de. Influência da irrigação e do genótipo na produção de castanha em cajueiro-anão-precoce. Pesquisa Agropecuária Brasileira, v.38, p.61-66, 2003. DOI: 10.1590/S0100-204X2003000100008. 
PAIVA, J.R. de; BARROS, L. de M.; CAVALCANTI, J.J.V.; MARQUES, G.V.; NUNES, A.C. Seleção de porta-enxertos de cajueiro comum para a região Nordeste: fase de viveiro. Revista Ciência Agronômica, v.39, p.162-166, 2008.

PAIVA, J.R. de; BARROS, L. de M.; CRISÓSTOMO, J.R.; ARAÚJO, J.P.P. de; ROSSETTI, A.G.; CAVALCANTE, J.J.V.; FELIPE, E.M. Depressão por endogamia em progênies de cajueiro-anão-precoce (Anacardium occidentale L.) var. Nanum. Pesquisa Agropecuária Brasileira, v.33, p.425-431, 1998.

PAIVA, J.R. de; BISCEGLI, C.I.; LIMA, A.C. Análise da castanha do cajueiro por tomografia de ressonância magnética. Pesquisa Agropecuária Brasileira, v.39, p.1149-1152, 2004. DOI: 10.1590/ S0100-204X2004001100014.

PONTE, L.F.A.; FERREIRA, O.S.; ALVES, F.A.L.; FERREIRA-SILVA, S.L.; PEREIRA, V.L.A.; SILVEIRA, J.A.G. da. Variabilidade de indicadores fisiológicos de resistência à salinidade entre genótipos de cajueiro-anão e gigante. Pesquisa Agropecuária Brasileira, v.46, p.1-8, 2011. DOI: 10.1590/ S0100-204X2011000100001.

SILVA, J.A.G. da; DANTAS, A.C.V.L.; SAMPAIO, R.S. Produção de mudas de cajueiro-anão-precoce em tubetes com diferentes substratos. Magistra, v.15, p.269-274, 2003.

SOARES, A.C.D.; COSTA, J.T.A.; CRISÓSTOMO, L.A.; MELO, F.I.O. Germinação de sementes e desenvolvimento de plântulas de cajueiro-anão-precoce submetidas a estresse salino. Revista Brasileira de Fruticultura, v.22, p.458-462, 2000.

SOUSA, A.B.O. de; BEZERRA, M.A.; FARIAS, F.C. Germinação e desenvolvimento inicial de clones de cajueiro comum sob irrigação com água salina. Revista Brasileira de Engenharia Agrícola e Ambiental, v.15, p.390-394, 2011. DOI: 10.1590/ S1415-43662011000400010.

Recebido em 7 de maio de 2013 e aprovado em 29 de agosto de 2013 